\title{
Assessment of antibacterial efficacy of Lugol's iodine compared with commercial hand sanitizers of Bangladesh
}

\author{
Md. Nafiur RAHMAN ${ }^{1}$, Mohammad ABDULLAH-AL-SHOEB ${ }^{1}$, Saaimatul HUQ ${ }^{2}$ and Muhammad ABUL KALAM AZAD ${ }^{1} \bowtie$ \\ ${ }^{1}$ Department of Biochemistry and Molecular Biology, Shahjalal University of Science and Technology, Sylhet-3114, Bangladesh \\ ${ }^{2}$ Molecular Biotechnology division, National Institute of Biotechnology, Savar, Dhaka-1349, Bangladesh \\ $\triangle$ Corresponding author's Email: makazad-bmb@sust.edu; DORCiD:0000-0002-6423-8144
}

\begin{abstract}
Introduction. Hand disinfection is an essential step to prevent infection, reduce morbidity and minimize health care costs in a community. Aim. In this study, the Lugol's iodine (2\%) solution was evaluated to use as an emergency hand sanitizer and compared with the three commercially available hand sanitizers (Hexisol, Sepnil and Handirub) of Bangladesh. Methods. These hand sanitizers were examined and analyzed by susceptibility test, minimum bactericidal concentration test and efficacy determination test. The agar diffusion test was used to assess the efficacy of the products against pathogenic Escherichia coli, Shigella flexneri, Staphylococcus aureus, Salmonella typhi and Streptococcus pneumoniae. Results. Handirub has inhibited all the test organisms with highest zones of inhibition ranging between $24.38 \mathrm{~mm}$ and $28.63 \mathrm{~mm}$ while Hexisol zone of inhibition was ranging from $13.3 \mathrm{~mm}$ to $15 \mathrm{~mm}$. Unfortunately, Sepnil was inactive against Salmonella typhi, with very poor performance against other test organisms. All the three commercial hand sanitizers were only bacteriostatic at $100 \%$ concentration, while both $2 \%$ and $1 \%$ iodine were $100 \%$ bactericidal. The comparative study of the efficacy determination tests revealed that the Hexisol, Sepnil and Handirub are 93.05\%, 85.99\% and 96.57\% effective against microorganism, respectively. Interestingly, both $2 \%$ and $1 \%$ of iodine solutions gave $100 \%$ reduction of viable bacteria during the efficacy determination test. Conclusion. It is concluded that $1 \%$ iodine showed better results against infection when compared to the other hand sanitizers used in this study. Recommendation. Lugol's iodine could be an effective alternative to hand washing to achieve asepsis for the health-care professional in emergency outreach program and water scarcity areas.
\end{abstract}

\author{
Research Article \\ PII: S225199391900021-9 \\ Rec. 13 July 2019 \\ Rev. 20 September 2019 \\ Pub. 25 September 2019
}

\section{Keywords}

Hand sanitizer,

Lugol's iodine,

Hand hygiene,

Minimum inhibitory

concentration

\section{INTRODUCTION}

A hand sanitizer or hand antiseptic is a supplement or alternative to hand washing with soap and water. Keeping hand clean is one of the most essential actions for the reduction of transmission of infectious diseases in the community and hospitals environment $[1,2]$. Cold viruses, flu viruses, and pathogenic bacteria are easily spread through public meeting places such as hospital, school, bus, office, etc. [3]. One gram of human feces which is about the weight of a paper clip can comprises one trillion of microorganisms [4]. Once someone coughed or sneezed or touched by some other contaminated object, the germ can spread easily from hands to hands. When these contaminated hands are not washed off, they can be passed from person to person and makes people sick [5].

A decent hand hygiene practice have been shown to be effective in various situations such as the reduction of gastrointestinal infection and diarrhea [6-8], alleviate the outbreaks of the Ebola-Virus Disease [9], lowers the rate of the respiratory illnesses, like common colds $[6,10]$, and finally overcome the global morbidity and minimize health care cost [11]. In a health care setting hand washing is mandatory procedure according to Centers for Disease Control and Prevention (CDCP) and it may protect us from thousands of microbes [6]. The CDC guideline reported that, about two million people get hospitalized each year due to infections and that around ninety thousands of these patients die as a result of their infections [12]. Improved hand hygiene practice by health care workers and better cleaning of common hospital equipment could reduce the probability of patients becoming colonized and lead to subsequent reductions in infectious diseases. Thus it was calculated that, routine hand hygiene could save one million lives per year [13]. 
Hand hygiene can be performed by the removal of microbes with ordinary soap and water, and/or hand antiseptic using an antimicrobial soap or an alcohol-based hand rub. Considering the importance of hand hygiene, the CDC issued a guideline endorsing that, the hand rub can be regularly used for decontaminating hands. The hand sanitizers are composed of alcohol, ethanol, isopropanol or propanol with a suggested concentration $[14,15]$. However, iodine-based hand sanitizers also used frequently and a povidone-iodine hand wash and hand rub products demonstrated efficacious virucidal products to help prevent infection and limit the spread of Ebola virus disease [16].

Some research already reported that, hand washing with soaps may result in cracked skin as soap can remove body's fatty acid from the skin, which then provides an entry portal for pathogens [17, 18]. On the other hand, eminent antiseptic has supplementary skincare product such as emollients, and recommended that the hand sanitizers are also well-suited by the skin [19]. Another great benefit of hand sanitizer is that it could play a vital role to prevent commonly transmissible pathogens in water lacking areas as it does not require water to wash hands. However, when use too frequently, the alcohol based hand sanitizers also can cause drying and cracking on skin. Moreover the alcohol-based hand sanitizers are classified as a fire hazard [14, 15]. Therefore, they should be stored out of child's reach and only should use with adult supervision. If ingested, alcohol toxicity can even lead to alcohol poisoning [15]. The iodine have persistent antimicrobial activity for a prolonged period and iodine-based hand sanitizers could be a good alternative for alcohol-based hand sanitizers.

This particular study was aimed to check out the efficacy of some alcohol-based hand sanitizers and a Lugol's iodine ( $2 \%$ iodine) formulation against bacteria of clinical importance using both dilution and diffusion susceptibility methods. This investigation serves to broaden the knowledge of the general public about the effect of hand sanitizers and also increases awareness on hand hygiene. Furthermore, this research might lead the manufacturers of these products to improve their products and make it more users friendly as well as a fetal tool for infectious microorganism.

\section{MATERIAL AND METHODS}

\section{Test isolates}

The clinical isolated used in this study were previously characterized and obtained from the Enteric Microbiology Laboratory of the International Central for Diarrheal Disease Research, Bangladesh. These isolates include the S. flexneri, S. aureus, S. typhi, E. coli, and S. pneumoniae. All isolates were stored in $-70^{\circ} \mathrm{C}$ until when needed.

\section{Hand sanitizers and Lugol's iodine}

Three brands of alcohol-based hand sanitizers were purchased from the local shop of Sylhet, Bangladesh. These are Hexisol, Sepnil, and Handirub (Table 1). Lugol's iodine solution (2\% iodine) prepared in the general laboratory of the Department of Biochemistry and Molecular Biology, Shahjalal University of Science and Technology (SUST) according to FDA manual [20]. The following table 1 was developed for showing the ingredients used in hand sanitizers.

Table 1. Hand sanitizers used in this study and their fundamental ingredients

\begin{tabular}{lll}
\hline Product Name & Active ingredients & Manufacturer name \\
\hline Hexisol & $\begin{array}{l}0.5 \% \mathrm{w} / \mathrm{v} \text { chlorhexidinegluconate, } \\
70 \% \mathrm{w} / \mathrm{w} \text { isopropyl alcohol }\end{array}$ & Advanced Chemical Industries Limited \\
\hline Sepnil & $62 \% \mathrm{wthanol}$ & Square Toiletries Limited \\
\hline Handirub & $\begin{array}{l}0.5 \% \mathrm{w} / \mathrm{v} \text { chlorhexidinegluconate, } \\
70 \% \mathrm{w} / \mathrm{w} \text { isopropyl alcohol }\end{array}$ & Eskayef Bangladesh Limited \\
\hline Lugol's Iodine & Potassium iodide and iodine crystal & Laboratory formulation \\
\hline
\end{tabular}

\section{Agar diffusion test (well variant)}

In this study, the agar diffusion method was used demonstrated by Valgas et al. [21]. This test was carried out as a preliminary screen to assess the antimicrobial activities of the various products. This involved the use of an inoculum corresponding to 0.5 [22]. The absorbance of the 0.5 McFarland standards was adjusted to 0.080.10 in $625 \mathrm{~nm}$ wavelengths. The prepared standard always keeps into a dark cabinet until needed [23]. MüllerHinton agar (MHA) was prepared for antibiotic susceptibility testing [24]. The test inoculum was swab 
inoculated to an MHA plate and allowed to stand at room temperature for 15 minutes. With the aid of a sterile 6 $\mathrm{mm}$ cork-borer, 4 equally spaced holes were bored in the agar plate with a fifth hole in the center of the plate. Fifty microliters $(50 \mu \mathrm{L})$ of the hand sanitizer was then introduced into each of the 4 wells while the central well was filled with an equal volume of sterile water to serve as a control. This was done for all the test organisms and hand sanitizers. The plates were incubated for 24 hours at $37^{\circ} \mathrm{C}$ in an upright position. They were then examined for zones of inhibition. The test was carried out in duplicates and the average of two readings was taken as the zone of inhibition in each case. Inhibition zones were measured with the aid of a ruler and all the measurement was taken as millimeter [21].

\section{Determination of minimum inhibitory concentration (MIC)}

MIC was carried out to determine the lowest concentration of test substances needed to prevent the growth of a given organism in vitro [25]. Various concentrations of the sanitizers were prepared in ascending order (40\%, 60\%, 80\%, and 100\%). In case of iodine solution, a formulation of $0.5 \%, 1 \%, 1.5 \%$, and $2 \%$ of iodine solutions were used. The tubes were incubated for 24 hours at $37^{\circ} \mathrm{C}$ and examined for visible growth or turbidity. The concentration of the sanitizer at which no visible growth was observed compared with the controls, was regarded as the MIC [26].

\section{Determination of minimum bactericidal concentration (MBC)}

MBC is the lowest concentration of a specific antimicrobial that kills $99.9 \%$ of cells of a given bacterial strain [25]. MBC was determined by assaying for live organisms in the tubes from the MIC tests which have shown no visible growth. A loop full of inoculums from the MIC tubes was streaked on fresh nutrient agar plates without the hand sanitizer incorporated into them. The plates were observed for growth after incubated at $37^{\circ} \mathrm{C}$ for 24 hours. Absence of growth indicated a bactericidal effect of the sanitizers at that concentration which is the MBC.

\section{Determination of efficacy of hand sanitizers in reducing viable counts of bacteria on the hands of subjects}

All the three commercial hand sanitizers and Lugol's iodine were further evaluated for their efficacy in reducing baseline bacterial counts of resident flora on the hands of subjects. Twenty individual volunteers were randomly selected for the study and verbal permission was obtained from all participating volunteers prior to the experiment. Before starting this procedure, the volunteers were well educated about correct hand disinfection procedure according to WHO [27]. The five randomly selected subjects hand were examined for baseline bacterial count reduction with each sample. Sterile nutrient agar plates were serially numbered and marked as with sanitizer and without sanitizer. At first, the test was carried out with unwashed hands of the subjects. Subjects' left hands were gently used to make a finger impression on the agar by pressing and rolling the finger on the agar in the plate marked as without sanitizer. After that, three milliliters of the sanitizer was applied to the hand and then rubbed thoroughly on the palm, hands, and fingernails until the hands became dry. Further the finger impression was repeated on the plate marked with sanitizer for all subjects. The plates were incubated for 24 hours at $37^{\circ} \mathrm{C}$ and after 24 hours the number of colonies was counted with a colony counter. The reduction in colony-forming unit (CFU) percentage was calculated to evaluate the efficacy of different hand sanitizers. The CFU percent reduction was determined by the following simple formula.

CFU percent reduction $=\frac{(\mathrm{A}-\mathrm{B}) \times 100 \%}{\mathrm{~A}}$

Where $A$ is the viable counts of microorganism before treatment

Where $B$ is the viable counts of microorganism after treatment

\section{RESULTS}

\section{Agar diffusion test}

In the susceptibility test, all the test products exhibited inhibitory activity against the test isolates (Table 2), except Sepnil against S. typhi. There was no inhibition zone for Sepnil against S. typhi (Figure 1), and also had lowest inhibition zone against S. flexneri, S. aureus, E.coli, and S. pneumoniae, which were $6.63 \mathrm{~mm}, 9.63 \mathrm{~mm}, 10.13$ $\mathrm{mm}$, and $8.30 \mathrm{~mm}$ respectively. Thus Sepnil was the least effective hand sanitizer to kill bacteria in agar diffusion test. Handirub gave better agar diffusion test result against $S$. aureus, E. coli, S. flexneri, and $S$. typhi by comparing with Hexisol and Sepnil. It showed the maximum diameter of the inhibition zone against $S$. typhi (27 
$\mathrm{mm}$ ) and lowest diameter of inhibition zone against E.coli $(25.38 \mathrm{~mm})$. The highest inhibition zones were observed by the $2 \%$ iodine and Handirub ranging from $24.38 \mathrm{~mm}$ to $28.63 \mathrm{~mm}$.

Table 2. Summary of the susceptibility patterns of test organism against different hand sanitizers

\begin{tabular}{lccccc}
\hline Sanitizers & \multicolumn{4}{c}{ Diameter of inhibition zones $(\mathbf{m m})$ of hand sanitizers against test organisms } \\
\cline { 2 - 6 } name & S. flexneri & S. aureus & S. typhi & E. coli & S. pneumoniae \\
\hline Hexisol & 15.00 & 13.13 & 14.50 & 14.50 & 16.50 \\
\hline Sepnil & 06.63 & 09.63 & 0 & 10.13 & 8.30 \\
\hline Handirub & 25.88 & 26.00 & 27.00 & 25.38 & 26.80 \\
\hline $2 \%$ iodine & 28.63 & 26.75 & 24.38 & 26.36 & 28.00 \\
\hline
\end{tabular}

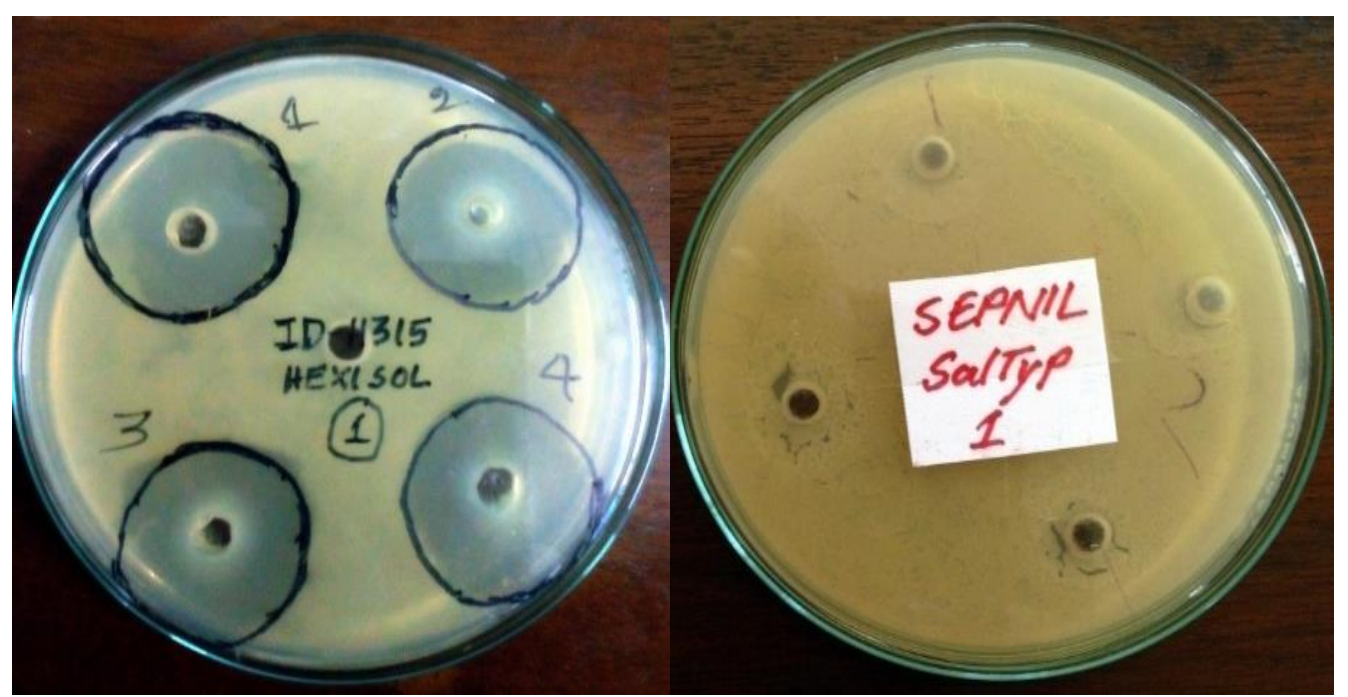

Figure 1. Sample MHA plate of Hexisol and Sepnil against S. flexneri and S. typhi respectively

\section{Minimum inhibitory concentration (MIC)}

All the commercially available hand sanitizers tested here had a MIC of 100\% (Table 3). At 80\% concentration, Handirub was effective against all the test organisms except Salmonella typhi, and Hexisol was effective against S. flexneri and S. aureus only (Table 3). Sepnil was not effective even at a concentration of $80 \%$ for any of the test organism. In the case of Lugol's iodine, inhibitions of all the test organisms were observed at $1 \%, 1.5 \%$, and $2 \%$ concentrations (Table 3 ). Thus only $1 \%$ of iodine is highly effective to kill all the test organisms used in this study.

Table 3. Minimum inhibitory concentration determination (MIC) test results

\begin{tabular}{|c|c|c|c|c|c|c|c|}
\hline \multirow{2}{*}{ Hand sanitizer } & \multirow{2}{*}{$\begin{array}{c}\text { Concentration } \\
\text { (\%) }\end{array}$} & \multicolumn{6}{|c|}{ Test organism } \\
\hline & & S. flexneri & S. aureus & S. typhi & E. coli & S. pneumoniae & MIC \\
\hline \multirow{4}{*}{ Hexisol } & 40 & + & + & + & + & + & \multirow{12}{*}{$100 \%$} \\
\hline & 60 & + & + & + & + & + & \\
\hline & 80 & - & - & + & + & + & \\
\hline & 100 & - & - & - & - & - & \\
\hline \multirow{4}{*}{ Sepnil } & 40 & + & + & N/A & + & + & \\
\hline & 60 & + & + & N/A & + & + & \\
\hline & 80 & + & + & N/A & + & + & \\
\hline & 100 & - & - & N/A & - & - & \\
\hline \multirow{4}{*}{ Handirub } & 40 & + & + & + & + & + & \\
\hline & 60 & + & + & + & + & + & \\
\hline & 80 & - & - & + & - & - & \\
\hline & 100 & - & - & - & - & - & \\
\hline \multirow{5}{*}{ Iodine } & 0.25 & + & + & + & + & + & \multirow{5}{*}{$1 \%$} \\
\hline & 0.50 & + & + & + & + & + & \\
\hline & 1.0 & - & - & - & - & - & \\
\hline & 1.5 & - & - & - & - & - & \\
\hline & 2.0 & - & - & - & - & - & \\
\hline
\end{tabular}




\section{Minimum bactericidal concentration (MBC)}

The contents of the $100 \%$ concentration tubes were further tested to determine the MBC. Unfortunately, the MBC test plates of commercial hand sanitizers showed the bacterial growth indicating that the products were only bacteriostatic against the organisms and not bactericidal. Interestingly, when the $2 \%$ iodine contents were plated on nutrient agar, there were no growths of test organisms. Similar results were also observed with the iodine concentration of $1.5 \%$ and $1 \%$. Thus $2 \%$ iodine appeared to be the more effective hand sanitizer option as it is highly bactericidal.

\section{Efficacy determination test}

The efficacy of hand sanitizers in reducing viable counts of bacteria on the hands of volunteers was determined after applying the hand sanitizers and $2 \%$ iodine individually. The internal ethics committee of SUST approved the study protocol and informed consent were taken from all the participants. There were no commercial hand sanitizers which can reduce the $100 \%$ viable bacterial count. The efficiency determination test revealed that Handirub had highest CFU reduction rate (96.57\%) by comparing with Hexisol and Sepnil (93.05\% and $85.99 \%$, respectively) (Table 4). However, $2 \%$ iodine formulation was highly effective for the reduction of viable bacterial count on volunteer's hand (100\%). The performance of Sepnil was only $85.99 \%$, which represent the lowest performance.

Table 4. Viable bacterial count reduction on Hands of volunteers

\begin{tabular}{lcccc}
\hline \multirow{2}{*}{ Volunteers no } & \multicolumn{4}{c}{ CFU percentage reduction } \\
\cline { 2 - 5 } & Hexisol & Sepnil & Handirub & 2\% iodine \\
\hline 1 & 98.16 & 82.72 & 97.12 & 100 \\
2 & 92.69 & 87.5 & 99.66 & 100 \\
3 & 94.39 & 85.34 & 96.86 & 100 \\
4 & 96.21 & 91.83 & 89.90 & 100 \\
5 & 83.79 & 85.5 & 99.32 & 100 \\
Average reduction & 93.05 & 85.99 & 96.57 & 100 \\
\hline
\end{tabular}

\section{DISCUSSION}

Hand hygiene is one of the most important parts to control infections and prevent various diseases [28, 29]. The importance of efficacy in choosing the right-hand hygiene product is reflected in the CDC guideline on hand hygiene [30]. An eminent and prescribed method of hygiene is hand sanitizing especially in a healthcare setting and in areas lacking adequate water supply [28]. We have evaluated the antibacterial efficacy of the most popular and available brands of hand sanitizers sold in Bangladesh. Laboratory preparation of $2 \%$ iodine was also used as a hand sanitizer in this study, which can be considered as a homemade hand sanitizer.

In this study, the commercially available hand sanitizers showed a variable level of efficiency in the MIC test. Although Hexisol and Handirub have chlorohexidine and isopropyl alcohol as their active ingredient, Hexisol showed a lower diameter of inhibition zone for S. aureus and S. typhi. This could be occurring due to the poor or prolonged storage of the products which could lead to increased temperature causing evaporation of the active ingredient. In addition, the diluted hand sanitizers did not show antibacterial activity in the MIC test. Thus the antibacterial effect in MIC tests was only observed with $100 \%$ concentration of commercial hand sanitizers. On the other hand, the laboratory formulation of $2 \%$ iodine was effective in a diluted form such as $1 \%$ during MIC test.

This study revealed a poor performance in the agar diffusion test of Sepnil, as the highest diameter of inhibition zone was only $10.13 \mathrm{~mm}$ against E. coli. Moreover, there was no zone of inhibition for S. typhi, which represent that this bacterium was resistant against Sepnil. The Sepnil also gave the lowest CFU reduction value among the four hand-sanitizers (Graph 1). The poor activity of Sepnil is probably due to the negative interactive effects of the additional ingredients such fragrance, emollients, humectants, and thickening agents added to them. Besides, Sepnil is a gel type hand sanitizer whereas the other two sanitizers sold in liquid form. Therefore, the efficacy of hand sanitizers is also affected by the types of the sanitizers and liquid form is more suited and well distributed to the skin when it is applied to hand. The same type of finding also obtained by Kramer and his colleagues and they recommended that alcohol-based gels should not replace liquid hand disinfects in hospitals [31]. 


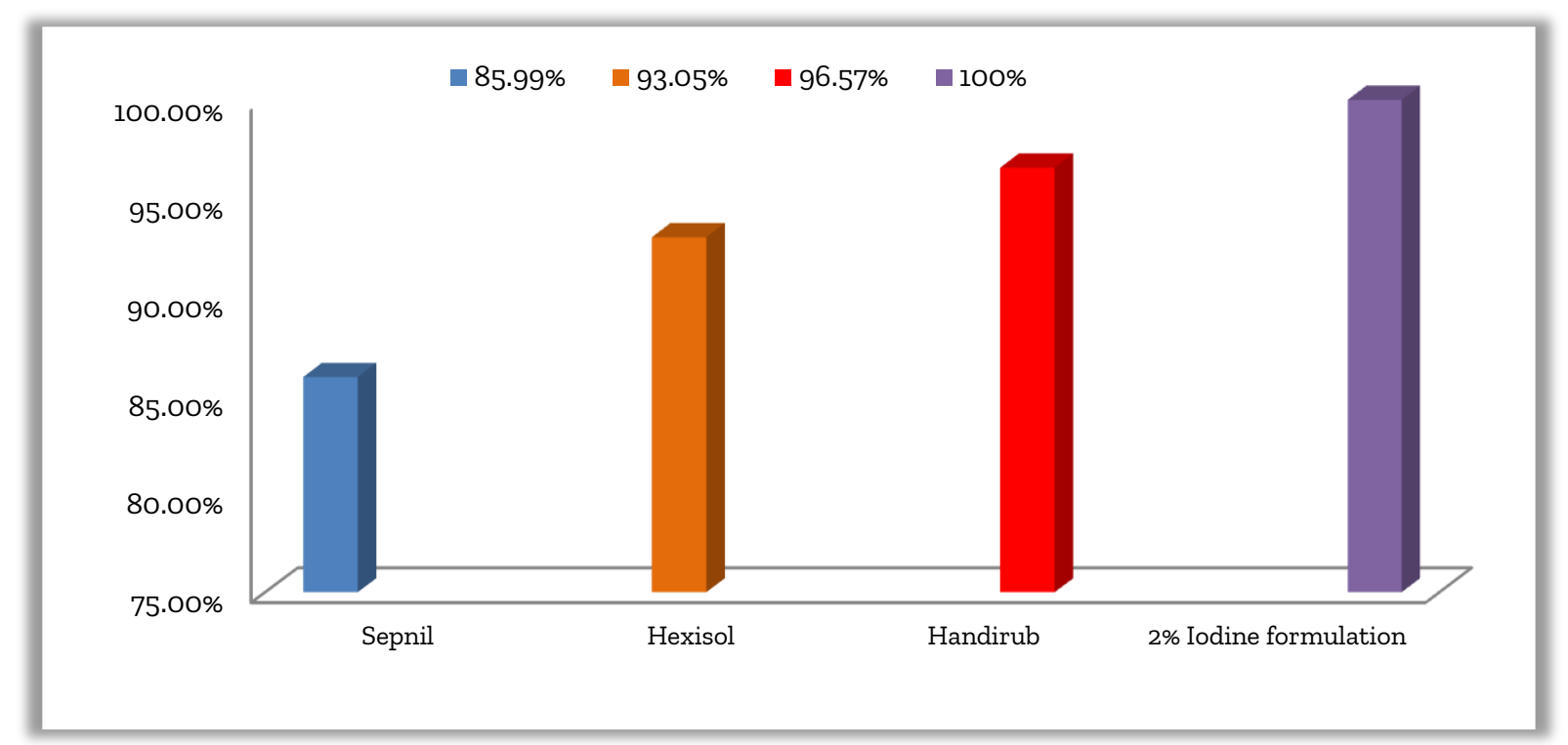

Graph 1. The overall efficiency of the used hand sanitizers to reduce the viable bacterial count

The CFU reduction rate for the commercial hand sanitizers was ranging from 85.99 to $96.57 \%$, although the manufactures claim is $99.9 \%$ leveled on the bottle. A useful and effective hand antiseptic is still lacking in Bangladesh. Government and proper authorities should take care of this issue because the effect of hand hygiene interventions on rates of gastrointestinal and respiratory illnesses is well known. As the hand hygiene is the simplest and most effective measure to reduce hospital-acquired infections [32], government and proper authorities should take care of this issue to certify the effective hand sanitizers.

This study also focused on a laboratory-made iodine-based hand sanitizer, as they are reported as antimicrobial agents for many years [33]. However, some Muslim health care workers also refuse to use alcoholbased hand sanitizers [34]. Thus an iodine-based hand sanitizer could be a good alternative. Previously, a different form of iodine such as tincture of iodine was used as an antiseptic [35]. Interestingly, 2\% iodine hand sanitizer was performed very accurately in the context of all kind of efficiency which represents it as strong hand sanitizers. Instead of all good antibacterial activity of iodine, there were some disadvantages of using it as hand sanitizer also. The iodine solution has an odd odor and a yellowish color, which might discourage to use of this iodine formulation. A further study is needed to establish this iodine formulation to use as a suitable hand sanitizer with good odor and color.

\section{CONCLUSION}

Proper hand hygiene is an important first-line defense against the spread of numerous infectious diseases. The commercially available hand sanitizers are not effective in this study, although the manufacturers claim that their products could kill 99.9\% germs in hands. Thus these hand sanitizers are not sufficient for our safety, and some hand sanitizer is proved for unfair claims. On the other hand, only $1 \%$ iodine is more effective than commercial hand sanitizers in preventing bacteria from the hands of individuals. Therefore there is a necessity to confirm the effectiveness of hand sanitizers sold in Bangladesh. Regulatory authorities and manufacturers should enforce stringent quality control measures and routine inspections during production to ensure the efficacy of these products and thus protect consumers from buying inferior products. Finally, in case of an emergency and water deficit areas of the world, only $1 \%$ iodine formulation can be used as a suitable and effective hand sanitizer verified in this study.

\section{DECLARATIONS}

\section{Acknowledgements}

This work was supported by SUST Research Grant of Shahjalal University of Science and Technology, Bangladesh. Our obligations to the Department of Biochemistry and Molecular Biology, Shahjalal University of Science and Technology, Sylhet, Bangladesh for technical support. A special thanks to the International Centre for Diarrhoeal Disease Research, Bangladesh (ICDDR, B) for providing the clinical isolates of microorganisms. 


\section{Authors' contributions}

All authors contributed equally to this work.

\section{Competing interests}

The authors declare that they have no competing interests.

\section{Consent to publish}

Not applicable.

\section{REFERENCES}

1. Pittet D, Allegranzi B, Sax H, Dharan S, Pessoa-Silva CL, Donaldson L, et al. Evidence-based model for hand transmission during patient care and the role of improved practices. The Lancet Infectious Diseases. 2006 Oct 1;6(10):641-52. (Search Google Scholar ; https://doi.org/10.1016/S1473-3099(06)70600-4)

2. Zapka C, Leff J, Henley J, Tittl J, Nardo ED, Butler M, et al. Comparison of standard culture-based method to cultureindependent method for evaluation of hygiene effects on the hand microbiome. mBio. 2017 May 3;8(2):eooog3-17. (Search Google Scholar ; https://doi.org/10.1128/mBio.00093-17)

3. Boone SA, Gerba CP. Significance of fomites in the spread of respiratory and enteric viral disease. Appl Environ Microbiol. 2007 Mar 15;73(6):1687-96. (Search Google Scholar ; https://doi.org/10.1128/AEM.02051-06)

4. Franks AH, Harmsen HJM, Raangs GC, Jansen GJ, Schut F, Welling GW. Variations of bacterial populations in human feces measured by fluorescent in situ hybridization with group-specific 16S rRNA-targeted oligonucleotide probes. Appl Environ Microbiol. 1998 Sep 1;64(9):3336-45. (Search Google Scholar ; https://doi.org/10.1128/AEM.64.9.33363345.1998)

5. Show Me the Science - Why Wash Your Hands? | Handwashing | CDC [Internet]. 2019 [cited 2019 Sep 4]. Available from: https://www.cdc.gov/handwashing/why-handwashing.html

6. Aiello AE, Coulborn RM, Perez V, Larson EL. Effect of hand hygiene on infectious disease risk in the community setting: a meta-analysis. Am J Public Health. 2008 Aug 1;98(8):1372-81. (Search Google Scholar ; https://doi.org/10.2105/AJPH.2007.124610)

7. Ejemot Nwadiaro RI, Ehiri JE, Arikpo D, Meremikwu MM, Critchley JA. Hand washing promotion for preventing diarrhoea. Cochrane Database of Systematic Reviews [Internet]. 2015 [cited 2019 Sep 4];(9). Available from: https://www.cochranelibrary.com/cdsr/doi/10.1002/14651858.CD004265.pub3/abstract (Search Google Scholar ; https://doi.org/10.1002/14651858.CDo04265.pub3)

8. Meadows E, Le Saux N. A systematic review of the effectiveness of antimicrobial rinse-free hand sanitizers for prevention of illness-related absenteeism in elementary school children. BMC Public Health. 2004 Nov 1;4(1):50. (Search Google Scholar ; https://doi.org/10.1186/1471-2458-4-50)

9. Wolfe $\mathrm{MK}$, Gallandat K, Daniels $\mathrm{K}$, Desmarais AM, Scheinman P, Lantagne D. Handwashing and Ebola virus disease outbreaks: A randomized comparison of soap, hand sanitizer, and $0.05 \%$ chlorine solutions on the inactivation and removal of model organisms Phi6 and E. coli from hands and persistence in rinse water. PLOS ONE. 2017 Feb 23;12(2):e0172734. (Search Google Scholar ; https://doi.org/10.1371/journal.pone.0172734)

10. Rabie T, Curtis V. Handwashing and risk of respiratory infections: a quantitative systematic review. Tropical Medicine \& International Health. 2006;11(3):258-67. (Search Google Scholar ; https://doi.org/10.1111/j.1365-3156.2006.01568.x)

11. Haque M, Sartelli M, McKimm J, Abu Bakar M. Health care-associated infections - an overview. Infect Drug Resist. 2018 Nov 15;11:2321-33. (Search Google Scholar ; https://doi.org/10.2147/IDR.S177247)

12. Zerr DM, Garrison MM, Allpress $A L$, Heath J, Christakis DA. Infection control policies and hospital-associated infections among surgical patients: variability and associations in a multicenter pediatric setting. Pediatrics. 2005 Apr 1;115(4):e387-92. (Search Google Scholar ; https://doi.org/10.1542/peds.2004-2014)

13. Curtis V, Cairncross S. Effect of washing hands with soap on diarrhoea risk in the community: a systematic review. The Lancet Infectious Diseases. 2003 May 1;3(5):275-81. (Search Google Scholar ; https://doi.org/10.1016/S14733099(03)00606-6)

14. Pickering AJ, Boehm AB, Mwanjali M, Davis J. Efficacy of waterless hand hygiene compared with handwashing with soap: a field study in Dar es Salaam, Tanzania. The American Journal of Tropical Medicine and Hygiene. 2010 Feb 1;82(2):270-8. (Search Google Scholar ; https://doi.org/10.4269/ajtmh.2010.09-0220)

15. Reynolds SA, Levy F, Walker ES. Hand Sanitizer Alert. Emerg Infect Dis. 2006 Mar;12(3):527-9. (Search Google Scholar ; https://doi.org/10.3201/eid1203.050955)

16. Eggers $\mathrm{M}$, Eickmann $\mathrm{M}$, Kowalski $\mathrm{K}$, Zorn J, Reimer K. Povidone-iodine hand wash and hand rub products demonstrated excellent in vitro virucidal efficacy against Ebola virus and modified vaccinia virus Ankara, the new European test virus for enveloped viruses. BMC Infectious Diseases. 2015 Sep 17;15(1):375. (Search Google Scholar ; https://doi.org/10.1186/s12879-015-1111-9) 
17. Larson EL, Norton Hughes CA, Pyrek JD, Sparks SM, Cagatay EU, Bartkus JM. Changes in bacterial flora associated with skin damage on hands of health care personnel. American Journal of Infection Control. 1998 Oct 1;26(5):513-21. (Search Google Scholar ; https://doi.org/10.1016/So196-6553(98)70025-2)

18. Winnefeld M, Richard MA, Drancourt M, Grob JJ. Skin tolerance and effectiveness of two hand decontamination procedures in everyday hospital use. British Journal of Dermatology. 2000;143(3):546-50. (Search Google Scholar ; https://doi.org/10.1111/j.1365-2133.2000.03708.x)

19. Boyce JM. Using Alcohol for Hand Antisepsis: Dispelling Old Myths. Infection Control \& Hospital Epidemiology. 2000 Jul;21(7):438-41. (Search Google Scholar ; https://doi.org/10.1086/501784)

20. Ngốc H. Bacteriological Analytical Manual. [cited 2019 Sep 30]; Available from: https://www.academia.edu/23345561/Bacteriological_Analytical_Manual ; Google Scholar

21. Valgas C, Souza SM de, Smânia EFA, Smânia Jr. A. Screening methods to determine antibacterial activity of natural products. Brazilian Journal of Microbiology. 2007 Jun;38(2):369-80. (Search Google Scholar ; https://doi.org/10.1590/S1517-83822007000200034)

22. McFarland J. The nephelometer: an instrument for estimating the number of bacteria in suspensions used for calculating the opsonic index and for vaccines. JAMA. 1907 Oct 5;XLIX(14):1176-8. (Search Google Scholar ; https://doi.org/10.1001/jama.1907.25320140022001f)

23. Cheesbrough M. District Laboratory Practice in Tropical Countries. Cambridge University Press; 2006. 464 p. (Search Google Scholar ; https://doi.org/10.1017/CBO9780511543470)

24. Atlas RM. Handbook of Microbiological Media [Internet]. CRC Press; 2004 [cited 2019 Sep 4]. Available from: https://www.taylorfrancis.com/books/9780429129032 (Search Google Scholar ; https://doi.org/10.1201/9781420039726)

25. Nester E, Anderson D, Roberts C, Nester M. Microbiology: a Human Perspective. 6th ed. The McGraw-Hill Companies, Inc. New York.; 2009. 480-481 p. (Google Scholar)

26. Oke MA, Bello AB, Odebisi MB, El-Imam AMA, Kazeem MO. Evaluation of antibacterial efficacy of some alcohol-based Hand sanitizers sold in Ilorin (North-Central Nigeria). Ife Journal of Science. 2013 Jan 1;15(1):111-117-117. (Search Google Scholar ; https://www.ajol.info/index.php/ijs/article/view/131391)

27. Babeluk R, Jutz S, Mertlitz S, Matiasek J, Klaus C. Hand hygiene - evaluation of three disinfectant hand sanitizers in a community setting. PLOS ONE. 2014 Nov 7:9(11):el11969. (Search Google Scholar ; https://doi.org/10.1371/journal.pone.0111969)

28. Kampf G, Kramer A. Epidemiologic background of hand hygiene and evaluation of the most important agents for scrubs and rubs. Clinical Microbiology Reviews. 2004 Oct 1;17(4):863-93. (Search Google Scholar ; https://doi.org/10.1128/CMR.17.4.863-893.2004)

29. Mathur P. Hand hygiene: Back to the basics of infection control. Indian J Med Res. 2011 Nov;134(5):611-20. (Search Google Scholar ; https://doi.org/10.4103/0971-5916.90985)

30. Boyce JM, Pittet D. Healthcare Infection Control Practices Advisory Committee, HICPAC/SHEA/APIC/IDSA Hand Hygiene Task Force. Guideline for Hand Hygiene in Health-Care Settings. Recommendations of the Healthcare Infection Control Practices Advisory Committee and the HICPAC/SHEA/APIC/IDSA Hand Hygiene Task Force. Society for Healthcare Epidemiology of America/Association for Professionals in Infection Control/Infectious Diseases Society of America. MMWR Recomm Rep. 2002 Oct 25:51(RR-16):1-45, quiz CE1-4. (Search Google Scholar ; https://doi.org/10.1086/503164)

31. Kramer A, Rudolph P, Kampf G, Pittet D. Limited efficacy of alcohol-based hand gels. The Lancet. 2002 Apr 27;359(9316):1489-90. (Search Google Scholar ; https://doi.org/10.1016/So140-6736(02)08426-X)

32. Bessonneau V, Clément $\mathrm{M}$, Thomas $\mathrm{O}$. Can intensive use of alcohol-based hand rubs lead to passive alcoholization? International Journal of Environmental Research and Public Health. 2010 Aug;7(8):3038-50. (Search Google Scholar ; https://doi.org/10.3390/ijerph7083038)

33. McDonnell G, Russell AD. Antiseptics and disinfectants: activity, action, and resistance. Clinical Microbiology Reviews. 1999 Jan 1;12(1):147-79. (Search Google Scholar ; https://doi.org/10.1128/CMR.12.1.147)

34. Ahmed QA, Memish ZA, Allegranzi B, Pittet D. Muslim health-care workers and alcohol-based handrubs. The Lancet. 2006 Mar 25;367(9515):1025-7. (Search Google Scholar ; https://doi.org/10.1016/So140-6736(06)68431-6)

35. Fleischer W, Reimer K. Povidone-iodine in antisepsis - state of the art. DRM. 1997;195(Suppl. 2):3-9. (Search Google Scholar ; https://doi.org/10.1159/000246022) 